\title{
Experimental and theoretical investigation of environmental media on very-high-cycle fatigue behavior for a structural steel
}

\author{
Guian Qian, Chengen Zhou, Youshi Hong* \\ State Key Laboratory of Nonlinear Mechanics, Institute of Mechanics, Chinese Academy of Sciences, Beijing 100190, PR China
}

Received 17 August 2010; received in revised form 29 October 2010; accepted 30 October 2010

Available online 2 December 2010

\begin{abstract}
Rotary bending fatigue tests were performed in laboratory air and 3.5\% $\mathrm{NaCl}$ aqueous solution to investigate the influence of environmental media on fatigue properties of a structural steel in high-cycle and very-high-cycle fatigue regimes. The results show that the fatigue strength of the structural steel in $3.5 \% \mathrm{NaCl}$ solution is remarkably degraded compared with the case tested in laboratory air. The fracture surfaces of specimens tested in different environments were examined to reveal the fatigue crack initiation characteristics. It shows that for specimens tested in $3.5 \% \mathrm{NaCl}$ solution, cracks originate via multiple surface initiation modes and cracking is intergranular; in addition, widespread secondary cracks feature on the fracture surface. Based on fatigue tests and fractography observations, a numerical model of crack initiation is proposed to describe the transition of fatigue initiation site from subsurface to surface for specimens tested in air and 3.5\% NaCl solution. The model reveals the influences of load, material strength, grain size, inclusion size and surface environmental media on the crack initiation site transition. It agrees well with the experimental observations.
\end{abstract}

(c) 2010 Acta Materialia Inc. Published by Elsevier Ltd. All rights reserved.

Keywords: Very-high-cycle fatigue; Aqueous environment; Fatigue strength; Fatigue crack initiation; Structural steel

\section{Introduction}

Very-high-cycle fatigue (VHCF) [1] (also named ultrahigh-cycle fatigue [2], ultra-long-life fatigue [3], or gigacycle fatigue [4]) of metallic materials is commonly regarded as fatigue failure at stress levels below conventional fatigue limit and the relevant fatigue life beyond $10^{7}$ loading cycles. The research of VHCF has become a new horizon in the field of metal fatigue since the early work of Naito et al. [5,6], who reported the occurrence of fatigue failure at loading cycles beyond $10^{7}$ and even longer than $10^{8}$ with specific fatigue characteristics for carburized steels. In recent years, the investigation of VHCF on metallic materials has attracted an increasing number of investigators in the fatigue research field (e.g. [7-22]) due to the growing requirements of engineering applications, including aircraft, automobile, ship, railway, bridge, etc., for which the metallic components

\footnotetext{
* Corresponding author. Tel.: +8610 82543966.

E-mail address: hongys@imech.ac.cn (Y. Hong).
}

and structures need to endure a fatigue life larger than $10^{7}$ or $10^{8}$ loading cycles, and even requiring $10^{10}-10^{11}$ life cycles of endurance in some vital cases.

One typical characteristic of VHCF for high-strength steels is that the $S-N$ curve includes two parts corresponding to subsurface and surface crack initiation, resulting in a stepwise or duplex shape [7-9]. Another distinct feature of crack initiation for VHCF is identified as a fisheye pattern on the fracture surface, which is mostly located at the specimen subsurface region and originates from a nonmetallic inclusion [3,8-10]. Murakami et al. [3] reported that the mechanism of subsurface crack initiation and the formation of the fisheye pattern are associated with the interaction of hydrogen embrittlement and cyclic damage. Bathias et al. [4] found that subsurface crack initiation can start from nonmetallic inclusions and microstructural inhomogeneities, e.g. perlite colonies and long platelets. The study [4] revealed that the probability of finding a sufficient stress concentration inhomogeneity is much bigger in the interior of the material than at the surface. 


\begin{tabular}{|c|c|c|c|}
\hline \multicolumn{4}{|c|}{ Nomenclature } \\
\hline E & Young's modulus & $w_{\mathrm{i}}^{a}$ & surface energy related to subsurface crack initia- \\
\hline$k_{\mathrm{w}}$ & $w_{\mathrm{i}} / w_{\mathrm{s}}$ & & tion in air \\
\hline$k_{\mathrm{W}}^{a}$ & $w_{\mathrm{i}}^{a} / w_{\mathrm{s}}^{a}$ & $w_{\mathrm{i}}^{s}$ & surface energy related to subsurface crack initia- \\
\hline$k_{\mathrm{W}}^{s}$ & $w_{\mathrm{i}}^{s} / w_{\mathrm{s}}^{s}$ & & tion in $3.5 \% \mathrm{NaCl}$ solution \\
\hline $\begin{array}{l}K_{\mathrm{IC}} \\
l\end{array}$ & $\begin{array}{l}\text { fracture toughness of material } \\
\text { grain radius }\end{array}$ & $w_{\mathrm{i}}$ & $\begin{array}{l}\text { surface energy related to subsurface crack initia- } \\
\text { tion }\end{array}$ \\
\hline$N_{\mathrm{f}}$ & fatigue failure cycles & $w_{\mathrm{s}}$ & surface energy related to surface crack initiation \\
\hline$N_{\mathrm{i}}$ & $\begin{array}{l}\text { fatigue cycles required for crack initiation at } \\
\text { subsurface }\end{array}$ & $w_{\mathrm{s}}^{a}$ & $\begin{array}{l}\text { surface energy related to surface crack initiation } \\
\text { in air }\end{array}$ \\
\hline$N_{\mathrm{s}}$ & $\begin{array}{l}\text { fatigue cycles required for crack initiation at } \\
\text { surface }\end{array}$ & $w_{\mathrm{s}}^{s}$ & $\begin{array}{l}\text { surface energy related to surface crack initiation } \\
\text { in } 3.5 \% \mathrm{NaCl} \text { solution }\end{array}$ \\
\hline$r$ & inclusion radius & $\sigma_{\max }$ & maximum applied stress \\
\hline$\Delta \tilde{U}$ & dimensionless unit increment of energy & $\Delta \sigma$ & stress amplitude \\
\hline$\Delta U_{\mathrm{i}}$ & unit increment of energy for subsurface crack & $\varphi$ & $0.5 \Delta \sigma / k$ \\
\hline$\Delta U_{\mathrm{s}}$ & $\begin{array}{l}\text { Initiation } \\
\text { unit increment of energy for surface crack initi- } \\
\text { ation }\end{array}$ & & $r / l$ \\
\hline
\end{tabular}

Nishijima and Kanazawa [11] attributed the reason why the fatigue life for internal failure is longer than that for a surface failure to the fact that the stress intensity factor for flaws in the interior is smaller than that at the surface for the same size defect. Some factors, such as loading frequency [12,13], surface finishing condition [14,15], microstructure state [16-18], etc., may affect the VHCF properties of high-strength steels. Results in Ref. [12] show an influence of loading frequency on fatigue strength for several cast aluminum alloys. The fatigue strength tested at a frequency of $20 \mathrm{kHz}$ is much higher than that tested at $75 \mathrm{~Hz}$. Furuya et al. [13] found that the loading frequency does not have any significant impact on the VHCF behavior of a high-strength steel. Shiozawa and $\mathrm{Lu}[14]$ found that for surface shot-peened specimens, subsurface crack initiation dominated due to the surface residual stress induced by shot peening. Itoga et al. [15] investigated the influence of surface notch on VHCF behavior of a structural steel. The studies revealed that surface notch decreases the possibility of subsurface crack initiation. Krupp et al. [18] studied the effect of the microstructure of austenitic-ferritic duplex steels on the fatigue damage of VHCF. It revealed that fatigue damage in the VHCF regime causes the formation of slip bands followed by initiation and propagation of microstructurally short cracks in a very localized manner and the plastic slip occurred firstly in the softer austenite phase of the material. Of these factors, the investigation of environmental media, i.e. environmentally induced fatigue resistance difference (corrosion fatigue) in VHCF regime, is not only of scientific interest, but also of obvious engineering importance since engineering components are inevitably subjected to the environment with an extent of corrosiveness. However, there are few experimental results $[7,19]$ on the effect of environmental media on VHCF behavior of high-strength steels. In addition, the mechanism of surface and subsurface crack initiation for specimens tested in air and environmental media is still not clear.

Therefore, in this article, the VHCF behaviors of a structural steel were tested with a rotary bending machine operating at a frequency of $52.5 \mathrm{~Hz}$; the testing environments were laboratory air and $3.5 \% \mathrm{NaCl}$ aqueous solution, so as to investigate the influence of environmental media on the variation of fatigue strength and cracking process. According to the fatigue testing data and scanning electron microscopy (SEM) observations of fracture surfaces, the effect of environmental media on the fatigue behavior at high-cycle and VHCF regimes was examined. The mechanism of crack initiation and propagation was discussed. Based on the fatigue tests and the observations, a crack initiation model was proposed to describe the transition of fatigue initiation site from subsurface to surface for specimens tested in various environmental media.

\section{Material and experimental method}

The material tested in this investigation is a structural steel $(40 \mathrm{Cr})$, which has a chemical composition (wt.\%)

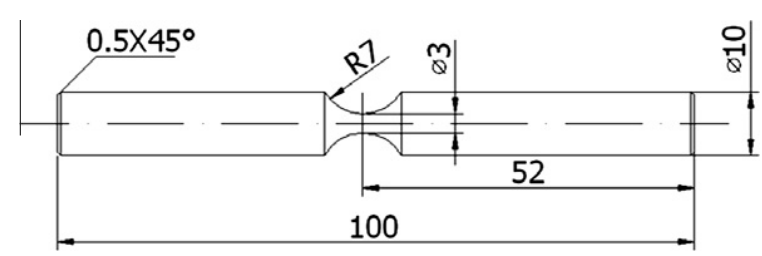

Fig. 1. Schematic drawing of an hourglass-shape specimen for rotary bending fatigue test (dimensions in $\mathrm{mm}$ ). 
of: $0.4 \mathrm{C}, 1 \mathrm{Cr}, 0.65 \mathrm{Mn}, 0.3 \mathrm{Si}$, balance Fe. Hourglass-shape specimens were machined with a minimum diameter of $3 \mathrm{~mm}$ and a round notch radius of $7 \mathrm{~mm}$, as shown in Fig. 1. The stress concentration factor for the specimen was calculated as 1.06. The raw specimens were heated at $1118 \mathrm{~K}$ for $2 \mathrm{~h}$ and oil quenched, then tempered at $473 \mathrm{~K}$ for $1 \mathrm{~h}$ and air cooled. Such heat-treated specimens have the microstructure of tempered martensite. The average size of original austenite grains is $11.2 \mu \mathrm{m}$ measured from 200 grains of intergranular morphology on SEM micrographs taken of fracture surfaces. The average ultimate tensile strength is $1768 \mathrm{MPa}$ from the tensile tests on four cylindrical specimens $(5 \mathrm{~mm}$ in diameter and $30 \mathrm{~mm}$ in gage length) with the same heat treatment procedure. Vickers microhardness indentation on the heat-treated specimen gives an average hardness value of $545 \mathrm{HV}$ with the uniform distribution over the specimen cross-section.

Fatigue tests were performed in laboratory air and 3.5\% $\mathrm{NaCl}$ aqueous solution by using a cantilever-type rotary bending machine at room temperature, which was operated at a frequency of $52.5 \mathrm{~Hz}$. The machine contains two pairs of rotary axes, each with two ends, and is capable of testing four specimens simultaneously. A weight was placed to the end of specimen through a fixture, which was converted to the applied maximum stress by a simple relation. Due to the feature of rotary bending scheme, the stress ratio was -1 throughout the tests. The experimental solution of $3.5 \% \mathrm{NaCl}$, with a $\mathrm{pH}$ value of 7.47 , was controlled to drip onto the specimen surface (10-15 drops per minute) through a plastic tube from a reserve tank, such that the specimen surface maintained a wet condition.

\section{3. $S-N$ curves}

The results of $S-N$ curves for specimens tested in laboratory air and $3.5 \% \mathrm{NaCl}$ aqueous solution are shown in Fig. 2, generally with the range of failure cycles (number of cycles to failure, $N_{\mathrm{f}}$ ) from $6 \times 10^{4}$ to $3 \times 10^{8}$, which passes high-cycle fatigue regime and enters into VHCF regime.

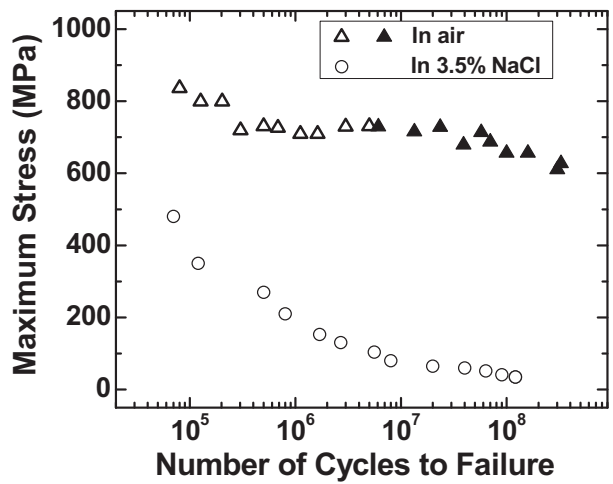

Fig. 2. Obtained $S-N$ curves for specimens tested in laboratory air and $3.5 \% \mathrm{NaCl}$ aqueous solution, showing fatigue strength substantially reduced due to the presence of aqueous solutions, with open symbols representing surface mode crack origination.
For fatigue testing in laboratory air, as shown in the upper part of Fig. 2, the $S-N$ curve exhibits a stepwise shape with a secondary inclined line, for which the fatigue failure occurs at stress levels below the conventional fatigue limit.

For fatigue testing in $3.5 \% \mathrm{NaCl}$ aqueous solution, the $S-N$ curve exhibits a continuously descending shape. As can be seen, the fatigue strength in $3.5 \% \mathrm{NaCl}$ aqueous solution is substantially lower than that in laboratory air and the reduction increases gradually with decreasing stress level. A similar trend is also found in Refs. [7,19], in which structural steels were tested in distilled water. It is further calculated from Fig. 2 that the ratio of the applied maximum stress for the case tested in $3.5 \% \mathrm{NaCl}$ aqueous solution to that in air at the failure life of $10^{7}$ is about $10 \%$, and is even lower $(5.8 \%)$ in the vicinity of $10^{8}$ failure cycles.

\section{Fatigue crack initiation}

The characteristics of fatigue crack initiation were examined by SEM and the crack origination modes are also presented in Fig. 2.

For the case of fatigue testing in laboratory air (triangular symbols in Fig. 2), crack origination mode is surfacerelated initiation for the specimens with fatigue life less than $10^{7}$ loading cycles and the corresponding stress levels are above $700 \mathrm{MPa}$, whereas the crack origination mode is subsurface initiation for the specimens with fatigue life beyond $10^{7}$ loading cycles and the stress levels are below $700 \mathrm{MPa}$. SEM observations showed that for the specimens cyclically fractured in laboratory air, the crack origination is due to a single origin for both surface and subsurface crack initiation.

Fig. 3a and $\mathrm{b}$ shows SEM micrographs for the testing case in laboratory air. Fig. 3a shows an example of fatigue crack initiation for a specimen surface in the high-cycle fatigue regime, without the participation of an inclusion. Fig. 3b shows an example of crack origination at the subsurface of specimen subjected to the maximum stress of $610 \mathrm{MPa}$ and breaking at a $\mathrm{VHCF}$ regime of $3.27 \times 10^{8}$ loading cycles, in which there is a fisheye pattern originated from a nonmetallic inclusion with main chemical compositions examined as $\mathrm{Al}, \mathrm{Ca}$ and $\mathrm{O}$. The average size of the inclusion located inside the fisheye and as a crack origin is $12 \mu \mathrm{m}$, obtained from 10 measurements.

For the case of fatigue tested in $3.5 \% \mathrm{NaCl}$ aqueous solution (circular symbols in Fig. 2), the crack origination observed by SEM for all the specimens is mainly caused by surface-related initiation. Additionally, unlike the single crack origin for specimens tested in air, multiple fatigue crack origins were observed for the specimens tested in $3.5 \% \mathrm{NaCl}$ aqueous solution (e.g. Fig. 4). The phenomenon of multiple crack origins for the case tested in $3.5 \% \mathrm{NaCl}$ aqueous solution suggests that the probability of crack initiation under corrosive environments is greatly increased. The presence of multiple crack origins is attributed to the locally inhomogenous stress concentration superimposed 

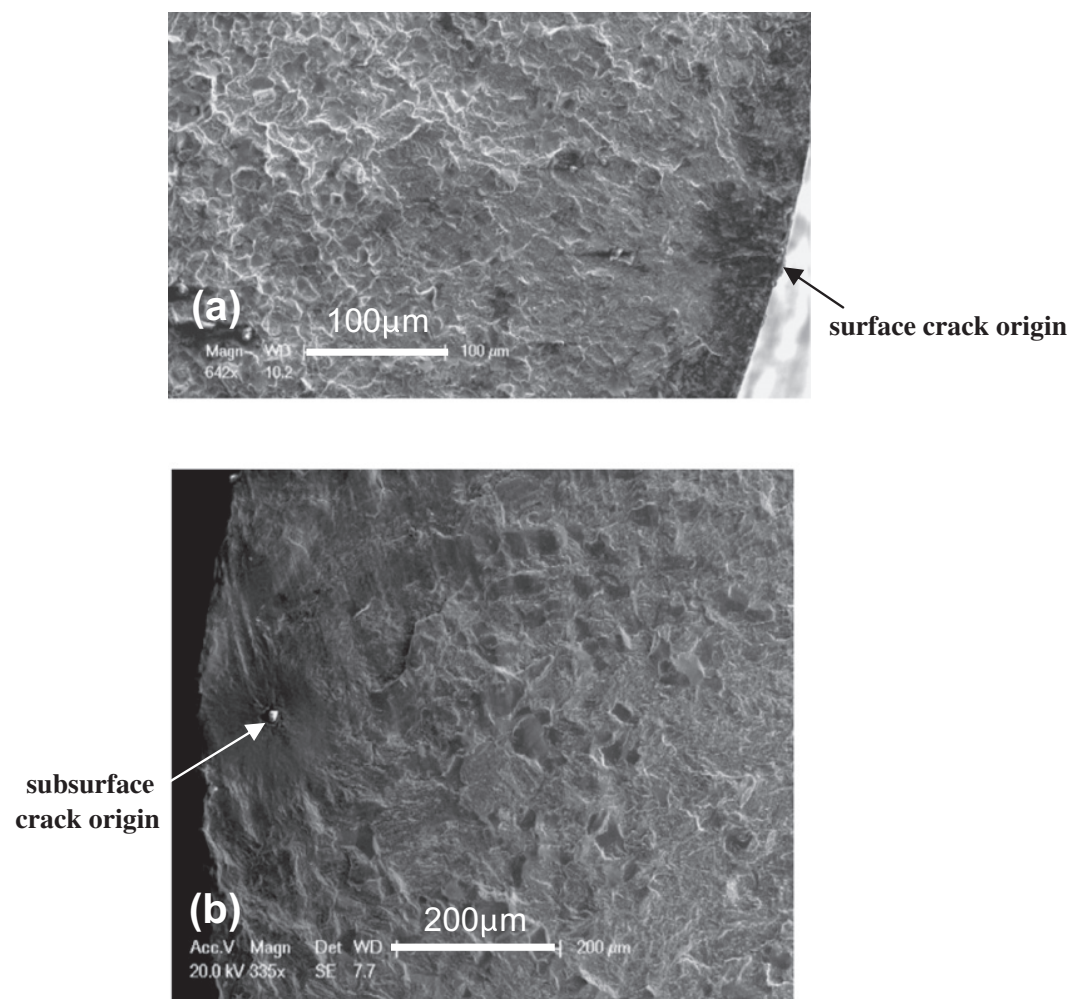

Fig. 3. Fractography of fatigue crack initiation for specimens tested in laboratory air: (a) crack origination at specimen surface at $\sigma_{\max }=720 \mathrm{MPa}$ and $N_{\mathrm{f}}=1.1 \times 10^{6}$, and (b) crack origination at specimen subsurface at $\sigma_{\max }=610 \mathrm{MPa}$ and $N_{\mathrm{f}}=3.27 \times 10^{8}$.

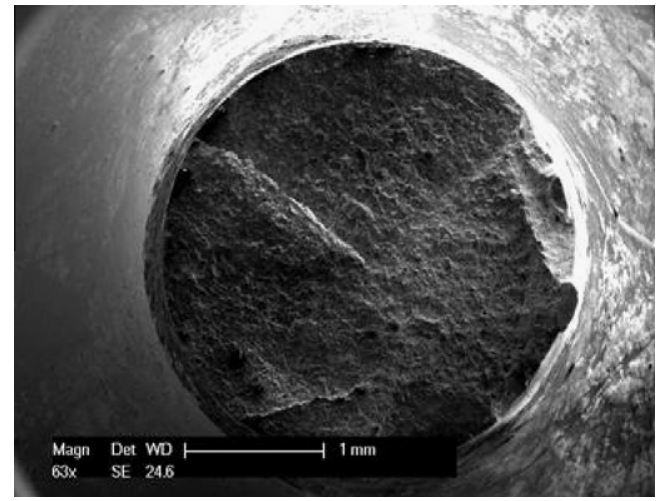

Fig. 4. Fracture surface of specimen tested in $3.5 \% \mathrm{NaCl}$ aqueous solution, showing multiple crack origins, $\sigma_{\max }=41.3 \mathrm{MPa}$ and $N_{\mathrm{f}}=9.0 \times 10^{7}$.

by the effect of aqueous media, which accelerates the fatigue damage process and degrades the fatigue strength of the high-strength steel tested.

Fig. 5 is a SEM micrograph showing fatigue crack initiation morphology of the specimen tested in $3.5 \% \mathrm{NaCl}$ aqueous solution with maximum applied stress $\sigma_{\max }=286 \mathrm{MPa}$ and $N_{\mathrm{f}}=2.52 \times 10^{7}$. It is seen that fatigue crack initiation in the VHCF regime is surface-crackinitiation dominant, while associated with subsurface micro-voids. The phenomenon of micro-void-associated crack initiation is commonly observed in the specimens tested in $3.5 \% \mathrm{NaCl}$ aqueous solution. Most micro-voids

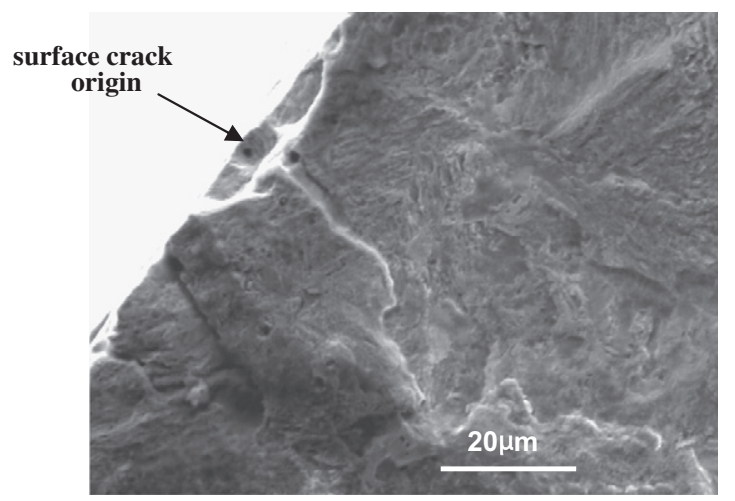

Fig. 5. Fatigue crack initiation morphology of specimen tested in $3.5 \%$ $\mathrm{NaCl}$ aqueous solution with $\sigma_{\max }=286 \mathrm{MPa}$ and $N_{\mathrm{f}}=2.52 \times 10^{7}$, showing surface layer crack initiation with a micro-void just underneath the surface.

involved in fatigue damage result from the decohesion of nonmetallic inclusions, which implies that crack damage may occur at specimen surface and propagate through the subsurface inhomogeneities such as inclusions. Then the surface cracking may coalesce with the growing micro-voids, leading to the crack propagation. The formation of micro-voids at inhomogeneities is probably related to the joint effect of the mechanical loading superimposed by aqueous environment.

Fig. 6 is another example of crack origin for fatigue testing in $3.5 \% \mathrm{NaCl}$ aqueous solution showing that the 


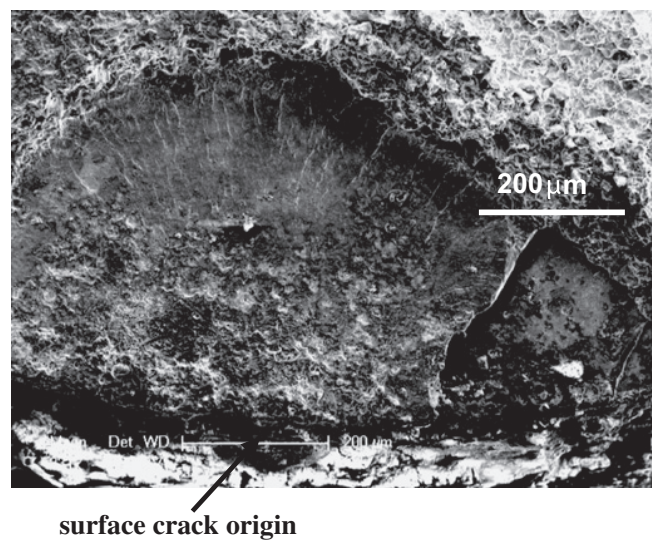

Fig. 6. Fractography of crack origin for a specimen tested in $3.5 \% \mathrm{NaCl}$ aqueous solution with $\sigma_{\max }=130 \mathrm{MPa}$ and $N_{\mathrm{f}}=2.68 \times 10^{6}$, showing the morphology of crack initiation and early growth zone.

initiation and early growth of a crack is mainly attributed to surface damage. This is early cracking stage of corrosion fatigue, i.e. cracks initiate at multiple sites of specimen surface layer by the process of surface damage combined with subsurface crack propagation, which is the result of mechanical cycling superimposed by the corrosive effect of test environment.

\section{Fatigue crack propagation}

For specimens tested in air, crack propagation displays transgranular cleavage-like morphology, as shown in Fig. $3 \mathrm{a}$ and $\mathrm{b}$, whereas, for the specimens tested in 3.5\% $\mathrm{NaCl}$ aqueous solution, the measurements on SEM micrographs show that the ratio of intergranular morphology is about $90 \%$ in fatigue crack steady growth zone, indicating that crack growth along grain boundaries is a dominant mechanism, as shown in Fig. 7. It is also seen that secondary cracks along grain boundaries widely existed, which is the phenomenon of grain boundary embrittlement due to the aqueous environmental effect.

Under aqueous environment, the failure mechanism of high-strength steel has been widely confirmed as hydrogeninduced embrittlement, e.g. Refs. [23-26]. One possible

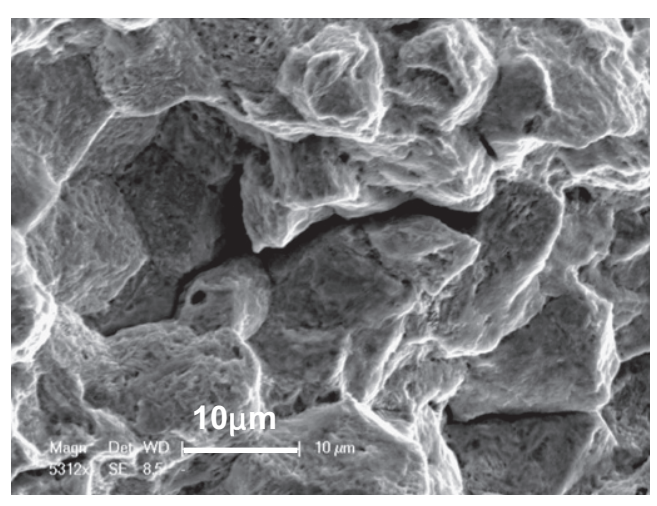

Fig. 7. Intergranular fracture morphology at crack steady growth zone, specimen tested in $3.5 \% \mathrm{NaCl}$ aqueous solution with $\sigma_{\max }=153 \mathrm{MPa}$ and $N_{\mathrm{f}}=1.7 \times 10^{6}$. mechanism is assumed that the hydrogen is trapped by dislocations or at grain boundaries $[23,24]$. Hydrogen effect is always superimposed by triaxial stress state or stress concentration due to the heterogeneity of material to cause stress corrosion cracking or corrosion fatigue $[25,26]$. In the present investigation of fatigue behavior in $3.5 \% \mathrm{NaCl}$ aqueous solution for the structural steel, it is observed that multiple crack origins exist and the fatigue crack initiation and early growth is surface cracking associated with subsurface microvoids mainly resulting from nonmetallic inclusions, which is the typical evidence of hydrogen-induced damage due to the effect of aqueous solution. It is also observed that after crack initiation and early growth, the process of crack propagation is dominantly intergranular morphology with widespread secondary microcracks, which is more typical evidence corresponding to hydrogen-induced cracking in corrosion fatigue.

\section{Crack initiation model}

In order to interpret the mechanism of fatigue crack initiation either at surface or at subsurface in different environmental media, a new parameter $D^{*}$ is proposed for this regard:

$D^{*}=\frac{N_{\mathrm{i}}}{N_{\mathrm{s}}}$

Thus, when $N_{\mathrm{s}}<N_{\mathrm{i}}$, i.e. $D^{*}>1$, cracks originate at the surface. On the contrary, when $N_{\mathrm{s}}>N_{\text {i }}$, i.e. $D^{*}<1$, cracks initiate at the subsurface (interior).

Note that crack initiation related to inclusions in this study is attributed to the weak cohesive state between inclusion and matrix. Under cyclic loading, a crack may easily form due to the interface debonding and grow into the matrix. In such a case, the subsurface crack initiation cycle $N_{\mathrm{i}}$ is [27]:

$N_{\mathrm{i}}=\frac{4 l w_{\mathrm{i}}}{\Delta U_{\mathrm{i}}}$

where $w_{\mathrm{i}}$ is surface energy related to subsurface crack initiation, $l$ is grain radius and $\Delta U_{\mathrm{i}}$ is unit increment of energy for subsurface crack initiation. $w_{\mathrm{i}}$ and $\Delta U_{\mathrm{i}}$ are functions of the grain radius $l$, the inclusion radius $r(\psi=r / l)$, the stress amplitude $\Delta \sigma$ and the resistance of dislocation movement $k$ $(\varphi=0.5 \Delta \sigma / k)$.

For fatigue crack initiation at surface, considering the surface crack factor and half cycling process [27], one has

$N_{\mathrm{s}}=\frac{2 l w_{\mathrm{s}}}{\Delta U_{\mathrm{s}}}$

where $\Delta U_{\mathrm{s}}$ is the unit increment of energy for surface crack initiation and $w_{\mathrm{s}}$ is surface energy related to subsurface crack initiation. Also, $w_{\mathrm{s}}$ and $\Delta U_{\mathrm{s}}$ are functions of the grain radius $l$, the inclusion radius $r$, the stress amplitude $\Delta \sigma$ and the resistance of dislocation movement $k$.

From Eqs. (2) and (3), one may write the following formula: 
$D^{*}=\frac{N_{\mathrm{i}}}{N_{\mathrm{s}}}=2 k_{\mathrm{w}} \frac{\Delta U_{\mathrm{s}}}{\Delta U_{\mathrm{i}}}$

where

$k_{\mathrm{w}}=\frac{w_{\mathrm{i}}}{w_{\mathrm{s}}}$

The further derivation to give the expression of $D^{*}$ :

$D^{*}=\frac{1.25 k_{\mathrm{w}}(\phi-1)^{2}}{\Delta \tilde{U} \psi^{2}}$

Here, the dimensionless unit increment of energy $\Delta \tilde{U}$ is

$\Delta \tilde{U}=\frac{\phi \Delta \tilde{\gamma}_{1}^{T}-\Delta \tilde{\gamma}_{1}^{L}+\phi^{2}}{2}$

with

$\Delta \tilde{\gamma}_{1}^{T}=\beta \varphi\left(2 \tilde{c}^{2}-1\right)+\frac{1}{\pi}\left(3 \sqrt{\tilde{c}^{2}-1}-2 \tilde{I}\right)-\frac{1}{4}$

$\Delta \tilde{\gamma}_{1}^{L}=\frac{2 \beta \varphi}{\pi}\left[\tilde{c}^{2} \cos ^{-1}\left(\frac{1}{\tilde{c}}\right)-\sqrt{\tilde{c}^{2}-1}+\frac{\pi}{2}\left(\tilde{c}^{2}-1\right)\right]$

$+\frac{2}{\pi^{2}}\left\{\sqrt{\tilde{c}^{2}-1}\left[\pi+\cos ^{-1}\left(\frac{1}{\tilde{c}}\right)\right]+2 \ln \left(\frac{1}{\tilde{c}}\right)-\pi \tilde{I}\right\}$

$\beta=1-\frac{1}{2 \varphi}-\frac{1}{\pi \varphi} \cos ^{-1}\left(\frac{1}{\tilde{c}}\right)$

$\tilde{c}=\frac{\psi}{2(\psi+2)}\left[1+\left(1+\frac{2}{\psi}\right)^{2}\right]$

and

$\tilde{I}=\frac{1}{\pi} \int_{1}^{\tilde{c}} \frac{t^{2}}{\sqrt{t^{2}-1}} \ln \left|\frac{t \sqrt{\tilde{c}^{2}-1}+\sqrt{\tilde{c}^{2}-t^{2}}}{t \sqrt{\tilde{c}^{2}-1}-\sqrt{\tilde{c}^{2}-t^{2}}}\right| \mathrm{d} t$

In short, Eq. (6) is the basic expression of $D^{*}$, which was used for the simulation and therefore the discussion of the competition mechanism for fatigue crack initiation at the surface or at the subsurface.

For the case tested in air, $k_{\mathrm{W}}^{a}$ is taken as unity in the calculation. Thus, we may calculate the values of $D^{*}$ as a function of $\varphi$ and $\psi$, and the results are shown in Fig. 8a. For the sake of clear description in the following discussion, it is useful to reiterate the definitions of $\varphi$ and $\psi: \varphi=0.5 \Delta \sigma /$ $k$, representing the ratio of applied stress $\Delta \sigma$ to dislocation resistance $k$, and $\psi=r / l$, with $r$ being the inclusion radius and $l$ the grain radius.

There is a horizontal line of $D^{*}=1$ in Fig. 8a. For the zone of $D^{*}>1$, cracks tend to initiate at the surface, whereas for $D^{*}<1$, cracks tend to originate at the subsurface. For the sake of further discussion, we define $\psi^{*}$ as the $\psi$ value corresponding to the intersection point between the distribution curve of $\varphi=16$ and the line of $D^{*}=1$. Thus, $\psi^{*}$ is about 0.2 . For a given loading state ( $\varphi$ in constant), when $\psi<\psi^{*}$, i.e. small inclusion size $r$ or large grain size $l$, if $D^{*}>1$, crack initiation tends to be at the surface. As $\psi$ increases, i.e. an increase in inclusion size $r$ or decrease in grain size $l$, the value of $D^{*}$ gradually decreases and leads
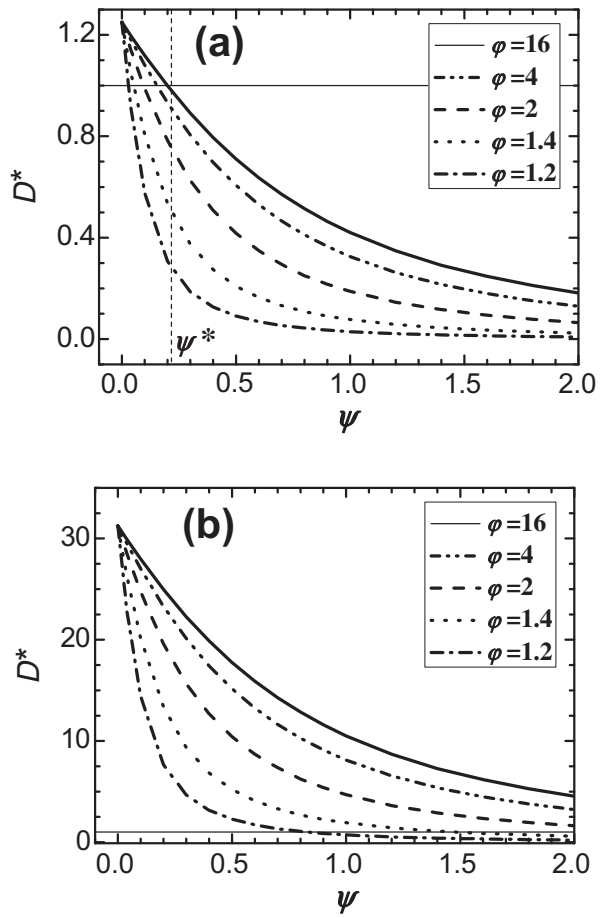

Fig. 8. Calculation results of $D^{*}$ vs. $\varphi$ and $\psi$ : (a) for specimens tested in air, and (b) for specimens tested in $3.5 \% \mathrm{NaCl}$ aqueous solution.

to $D^{*}<1$, the fatigue crack initiation shifts from surface to subsurface. On the other hand, when $\psi$ is given, the value of $D^{*}$ decreases with the decreasing of $\varphi$ (decrease of loading level $\Delta \sigma$ or increase of dislocation resistance $k$, i.e. strength of material). Thus, fatigue cracks tend to initiate at the subsurface. This may explain the above fracture surface observations that surface crack initiation occurs at shorter fatigue cycles under relatively higher loading level and subsurface crack origination happens at longer fatigue cycles under relatively lower loading level.

The surface fracture work in different environmental media can be expressed by:

$w_{\mathrm{s}} \propto \frac{K_{\mathrm{IC}}^{2}}{E}$

where $K_{\mathrm{IC}}$ is the fracture toughness of material and $E$ is Young's modulus.

For the brittle material, the fracture work is equal to the surface energy of growing a new crack surface. For the material tested in the present study, the fracture toughness in air and $3.5 \% \mathrm{NaCl}$ solution is $\sim 50 \mathrm{MPa} \mathrm{m}^{1 / 2}$ and $\sim 10 \mathrm{MPa} \mathrm{m}{ }^{1 / 2}$, respectively $[28,29]$. Thus, the ratio of surface energy related to surface crack initiation in air $\left(w_{\mathrm{s}}^{a}\right)$ to that in $3.5 \% \mathrm{NaCl}\left(w_{\mathrm{s}}^{s}\right)$ is expressed as:

$\frac{w_{\mathrm{s}}^{a}}{w_{\mathrm{s}}^{s}}=\frac{25}{1}$

We assume that environmental media have an influence only on the surface energy related to surface crack initiation, and do not affect the surface energy related to subsurface crack initiation, thus: 
$\frac{k_{\mathrm{W}}^{a}}{k_{\mathrm{W}}^{s}}=\frac{1}{25}$

where $k_{\mathrm{W}}^{a}=w_{\mathrm{i}}^{a} / w_{\mathrm{s}}^{a}$ and $k_{\mathrm{W}}^{s}=w_{\mathrm{i}}^{s} / w_{\mathrm{s}}^{s}$.

Considering Eqs. (6) and (15), $D^{*}$ for the fatigue tested in $3.5 \% \mathrm{NaCl}$ aqueous solution could be expressed as:

$D^{*}=\frac{N_{\mathrm{i}}}{N_{\mathrm{s}}}=\frac{1.25 \times 25(\varphi-1)^{2}}{\Delta \tilde{U} \psi^{2}}$

Thus, the values of $D^{*}$ for specimens tested in 3.5\% $\mathrm{NaCl}$ aqueous solution as a function of $\varphi$ and $\psi$ were calculated and shown in Fig. 8b. $D^{*}$ displays similar relation with $\varphi$ and $\psi$, compared to the case in air. However, it is clear that for specimens tested in $3.5 \% \mathrm{NaCl}$ solution, $D^{*}$ ranges from 0 to 30 , which is much bigger than that of specimens tested in air at the same value of $\varphi$ and $\psi$. It implies that the surface crack initiation is dominant for specimens tested in $3.5 \% \mathrm{NaCl}$, which is in accordance with the experimental observations.

In general, fatigue crack initiation tends to be at the subsurface at relatively low cyclic loading level, high strength of material, large inclusion size, small grain size and air environment, and vice versa. Therefore, it provides an insight to the material processing techniques in order to improve the fatigue life of the material.

\section{Conclusions}

According to the experimental and theoretical investigation of high-cycle and VHCF behaviors for a structural steel, the following conclusions are drawn:

(1) In air environment, a stepwise shape $S-N$ curve presents as fatigue life extends from high-cycle to VHCF regimes. Fatigue crack initiation is of single origin and crack origination is subsurface mode at VHCF regime.

(2) In $3.5 \% \mathrm{NaCl}$ aqueous solution, fatigue strength is greatly degraded. The ratio of the applied maximum stress in $3.5 \% \mathrm{NaCl}$ solution to that in air is only $10 \%$ for $10^{7}$ failure cycles, and is even lower $(5.8 \%)$ in the vicinity of $10^{8}$ failure cycles.

(3) The distinct characteristics of fractography for specimens tested in $3.5 \% \mathrm{NaCl}$ aqueous solution are (a) multiple crack originations, (b) surface cracking coalesced with subsurface growing micro-voids in early crack growth period, and (c) intergranular mode with widespread secondary cracks in the fatigue crack steady propagation period.

(4) A parameter model was proposed to interpret the mechanism of crack initiation at surface or at subsurface for specimens tested in air and in $3.5 \% \mathrm{NaCl}$ solution. The results show that, at relatively low loading level, the possibility of crack initiation at the subsurface increases with respect to large inclusion size, small grain size, large strength of material and air environment, which agrees well with the experimental observations.

\section{Acknowledgements}

This work was funded by the National Natural Science Foundation of China (Nos. 10772178 and 10721202) and the Knowledge Innovation Program of the Chinese Academy of Sciences (No. KJCX2-YW-L07). The authors are thankful to Professor Tatsuo Sakai of Ritsumeikan University of Japan for his generously providing the rotary bending machine.

\section{References}

[1] Stanzl SE, Tschegg EK, Mayer H. Int J Fatigue 1986;8:195.

[2] Lukáš P, Kunz L. Fatigue Fract Eng Mater Struct 2002;25:747.

[3] Murakami Y, Yokoyama NN, Nagata J. Fatigue Fract Eng Mater Struct 2002;25:735.

[4] Bathias C, Paris PC. Gigacycle fatigue in mechanical practice. New York: Marcel Dekker; 2005.

[5] Naito T, Ueda H, Kikuchi M. Jpn Soc Mater Sci 1983;32:1162.

[6] Naito T, Ueda H, Kikuchi M. Met Trans A 1984;15A:1431.

[7] Nakajima M, Tokaji K, Itoga H, Ko H-N. Fatigue Fract Eng Mater Struct 2003;26:1113.

[8] Sakai T, Sato Y, Oguma N. Fatigue Fract Eng Mater Struct 2002;25:765.

[9] Zhou C, Qian G, Hong Y. Key Eng Mater 2006;324-325:1113.

[10] Qian G, Hong Y, Zhou C. Eng Failure Anal 2010;17:1517.

[11] Nishijima S, Kanazawa K. Fatigue Fract Eng Mater Struct 1999;22:601.

[12] Engler-Pinto CC, Frisch RJ, Lasecki JV, Mayer H, Allison JE. Effect of frequency and environment on high cycle fatigue of cast aluminium alloys. In: Proc VHCF 4. Ann Arbor; 2007. p. 421.

[13] Furuya Y, Matsuoka S, Abe T, Yamaguchi K. Scripta Mater 2002;46:157.

[14] Shiozawa K, Lu L. Fatigue Fract Eng Mater Struct 2002;25:813.

[15] Itoga H, Tokaji K, Nakajima M, Ko H-N. Int J Fatigue 2003;25:379.

[16] Dominguez Almaraz GM. Mech Mater 2008;40:636.

[17] Makino T. Int J Fatigue 2008;30:1409.

[18] Krupp U, Helge K, Christ H, Köster P, Fritzen C. Int J Fatigue 2010;32:914.

[19] Tokaji K, Ko H-N, Nakajima M, Itoga H. Mater Sci Eng A 2003;345:197.

[20] Ranc N, Wagner D, Paris PC. Acta Mater 2008;56:4012.

[21] Sakai T, Lian B, Takeda M, Shiozawa K, Oguma N, Ochi Y, et al. Int J Fatigue 2010;32:497.

[22] Sohar CR, Betzwar-Kotas A, Gierl C, Weiss B, Danninger H. Int J Fatigue 2008;30:1137.

[23] McMahon Jr CJ. Eng Fract Mech 2001;68:773.

[24] Taha A, Sofronis P. Eng Fract Mech 2001;68:803.

[25] Nagumo M, Shimura H, Chaya T, Hayashi H, Ochiai I. Mater Sci Eng A 2003;348:192.

[26] Nagao A, Kuramoto S, Ichitani K, Kanno M. Scripta Mater 2001;45:1227.

[27] Tanaka T, Mura T. J Appl Mech Trans ASME 1981;48:97.

[28] Alloy steels compiling group of the metallurgical industry ministry. Alloy steels handbook. Publishing House of the Metallurgical Industry; 1983 [in Chinese].

[29] Suresh S. Fatigue of materials. Cambridge: Cambridge University Press; 1998. 